\begin{tabular}{|c|c}
\hline $\begin{array}{c}\text { Jurnal Pengabdian Kesehatan Komunitas } \\
\text { (Journal of Community Health Service) }\end{array}$ \\
https://jurnal.htp.ac.id/index.php/jpkk \\
\hline
\end{tabular}

\title{
Peningkatan Pengetahuan Masyarakat Dalam Pencegahan Hipertensi Serta Pengukuran Tekanan Darah Untuk Deteksi Dini Hipertensi
}

\author{
Agus Alamsyah, Ikhtiaruddin, Yuyun Priwahyuni, Christine Vita Gloria Purba
}

Prodi Kesehatan Masyarakat, STIKes Hang Tuah Pekanbaru

Email ${ }^{1}$ :agusalamsyah@htp.ac.id

\begin{tabular}{|c|c|}
\hline Histori artikel & Abstrak \\
\hline $\begin{array}{l}\text { Received: } \\
\text { 24-05-2021 } \\
\\
\text { Accepted: } \\
25-05-2021 \\
\\
\text { Published: } \\
26-05-2021\end{array}$ & $\begin{array}{l}\text { Penyakit hipertensi merupakan urutan pertama jenis penyakit } \\
\text { kronis tidak menular yang dialami oleh kelompok usia lanjut di Provinsi } \\
\text { Riau dan di Kota Pekanbaru. Kasus hipertensi pada tahun } 2020 \text { di } \\
\text { Puskesmas Rawat Inap Karya Wanita menempati urutan nomor } 2 \text { setelah } \\
\text { penyakit ISPA. Puskesmas Rawat Inap Karya Wanita mempunyai } \\
\text { beberapa wilayah kerja diantaranya adalah Kelurahan Limbungan Baru. } \\
\text { Kasus hipertensi di Kelurahan Limbungan Baru tertinggi kasusnya } \\
\text { teurutama di RW 03. Metode yang digunakan dalam pengabdian } \\
\text { masyarakat adalah dengan memberikan materi tentang hipertensi dan } \\
\text { mengukur tekanan darah untuk deteksi dini hipertensi karena posyandu } \\
\text { lansia pada saat pandemic covid-19 tidak buka. Untuk mengukur } \\
\text { keberhasilan dari kegiatan pengabdian masyarakat maka dilakukan pre dan } \\
\text { post mengenai pengetahuan peserta. Dari hasil Pre test dapat terlihat bahwa } \\
\text { dari } 27 \text { orang yang mengikuti kegiatan tersebut, hanya } 17 \text { (63 \% ) peserta } \\
\text { yang mengetahui apa itu penyakit hipertensi beserta bagaimana cara } \\
\text { pencegahannya dan dari } 27 \text { orang yang di ukur tekanan darahnya ada } \\
\text { sebanyak } 7 \text { orang (26\%) yang tekanan darahnya dikategorikan hipertensi, } \\
\text { ada } 2 \text { orang (7,5\%) yang tekanan darahnya dikategorikan hipotensi dan } 18 \\
\text { orang (66,5\%) yang tekanan darahnya normal. Setelah Post Test didapat } \\
\text { bahwa dari } 27 \text { orang peserta yang mengikuti kegiatan tersebut } 21 \text { ( } 77,8 \%) \\
\text { peserta mengetahui dan dapat menyebutkan satu persatu urutan dari materi } \\
\text { ataupun pencegahan hipertensi tersebut dan } 6 \text { (22,2\%). Disarankan kepada } \\
\text { pihak-pihak yang terkait seperti puskesmas bekerjasama dengan kepala } \\
\text { Desa, untuk dapat memaksimalkan kegiatan penyuluhan tentang hipertensi } \\
\text { dan penyakit menular lainnya serta mengaktifkan kembali kegiatan } \\
\text { posyandu lansia dimasa pandemik covid-19 dengan tetap menerapkan } \\
\text { protokol kesehatan. }\end{array}$ \\
\hline
\end{tabular}


Kata Kunci: Pengetahuan, Hipertensi, Tekanan darah, Kelurahan limbungan baru

The first disease hypertension is not infectious chronic illnesses experienced by age group in the Riau and in Pekanbaru. Cases of hypertension in 2020 in patient health centers work women ranked number 2 tract after disease. Patient health centers work women have several areas such as new Limbungan are in work. New cases of hypertension at the highest limbungan his case in RW 03. Methods used in devotion by giving the material about hypertension and measure blood pressure to early detection hypertension because most of them are elderly pandemic covid19 not open at the time .To measure the success of the community devotion and extension pre and post about participant knowledge. From the pre test can look that of 27 people participating in these activities, only 17 ( $63 \%$ ) participant was aware that diseases hypertension and how pencegahannya 27 and from those who are on their blood pressure monitor there were as many as 7 people ( $26 \%$ ) that his blood pressure are hypertension, 2 is the (7,5\%) that his blood pressure are hypotension and 18 the (66,5\%) his blood pressure is normal .After post test found that of 27 participants that participating in these activities $21(77,8) \%$ informed participants and to tell one by one the order of hypertension and the preventive or material (22,2\%) 6. Was recommended to such as puskesmas working pihak-pihak associated with the village head, to maximize extension activities about hypertension and other infectious diseases and turn back posyandu elderly provided pandemics covid-19 health protocol still apply.

Keywords: Knowledge, hypertension, blood pressure, Urban village limbungan baru

Copyright (c) 2021 Agus Alamsyah

\section{PENDAHULUAN}

Hipertensi merupakan salah satu penyakit tidak menular yang menjadi masalah kesehatan yang sangat serius. Hipertensi atau tekanan darah tinggi adalah suatu peningkatan abnormal tekanan darah dalam pembuluh darah arteri secara terus-menerus lebih dari suatu periode. Menurut WHO, batasan tekanan darah yang masih dianggap normal adalah 140/90 $\mathrm{mmHg}$, sedangkan tekanan darah $\geq 160 / 95 \mathrm{mmHg}$ dinyatakan sebagai Hipertensi. Tekanan darah di antara normotensi dan Hipertensi disebut borderline hypertension (Garis Batas Hipertensi). Batasan WHO tersebut tidak membedakan usia dan jenis kelamin (Adam, 2019).

Badan Kesehatan Dunia (WHO) pada tahun 2011 mencatat hingga satu miliar orang di dunia mengalami hipertensi dan dua pertiga di antaranya berada di negara berkembang 
yang berpenghasilan rendah-sedang. Statistik Kesehatan Dunia tahun 2012 WHO melaporkan bahwa hipertensi adalah suatu kondisi berisiko tinggi yang menyebabkan sekitar 51 persen dari kematian akibat stroke dan 45 persen dari penyakit jantung koroner (WHO dalam Republika, 2013). Sepertiga penduduk Amerika yang berusia 18 tahun ke atas menderita hipertensi, setidaknya hipertensi ringan (WHO dalam Faisal, 2011).

Prevalensi Hipertensi yang tinggi tidak hanya terjadi di negara maju tetapi juga di negara berkembang seperti di Indonesia. Berdasarkan hasil Riset Kesehatan Dasar (RISKESDAS) tahun 2018 menunjukkan angka prevalensi Hipertensi hasil pengukuran mencapai $34,1 \%$ meningkat tajam dari $25,8 \%$ pada tahun 2013 , dengan angka prevalensi tertinggi di Provinsi Kalimantan Selatan sebesar 44,1\% dan terendah di provinsi Papua sebesar 22,2\% (Riskesdas, 2018).

Hipertensi menempati urutan nomor 4 dari 10 penyakit terbanyak rawat inap di Rumah Sakit Provinsi Riau tahun 2018 yaitu 5148 kasus. Penyakit hipertensi merupakan urutan pertama jenis penyakit kronis tidak menular yang dialami oleh kelompok usia lanjut di Provinsi Riau dan di Kota Pekanbaru (Riskesdas, 2018). Kasus hipertensi pada tahun 2020 di Puskesmas Rawat Inap Karya Wanita menempati urutan nomor 2 setelah penyakit ISPA. Puskesmas Rawat Inap Karya Wanita mempunyai beberapa wilayah kerja diantaranya adalah Kelurahan Limbungan Baru. Kasus hipertensi di Kelurahan Limbungan Baru tertinggi kasusnya teurutama di RW 03. Berdasarkan latar belakang tersebut kami tertarik untuk mengadakan pengabdian kepada masyarakat di Kelurahan Limbungan Baru RW 03 dalam bentuk penyuluhan kesehatan mengenai hipertensi dan pemeriksaaan tekanan darah.

\section{TUJUAN PENGABDIAN}

Tujuan dari kegiatan pengabdian ini yaitu agar masyarakat di Wilayah kerja puskesmas Rejosari mengetahui dan memahami tentang penyakit Hipertensi dan dapat melakukan upaya pencegahannya serta Deteksi dini hipertensi.

\section{METODE PENGABDIAN}

Kegiatan pengabdian dilakukan dalam bentuk pengukuran tekanan darah dan penyuluhan kesehatan untuk memberikan informasi dan edukasi mengenai HIPERTENSI. Untuk kegiatan penyuluhan menggunakan metode ceramah dan Fokus Group Diskusi. Alat bantu yang digunakan dalam penyuluhan yaitu sound system, flipchart serta leaflet yang diberikan kepada tiap masyarakat yang hadir. Untuk Mengukur tekanan darah menggunakan tensimeter air raksa manual yang sudah dikalibrasi. Pelaksanaan pengabdian dilakukan 
Kelurahan Limbungan Baru RW 03 yang merupakan wilayah kerja Puskesmas Karya Wanita. Masyarakat yang hadir dalam kegiatan pengabdian ini merupakan ibu-ibu dan bapak-bapak berjumlah 27 orang dan 2 orang diantaranya merupakan kader kesehatan. Kegiatan pengabdian terdiri dari tahapan persiapan, tahapan pelaksanaan dan monitoring evaluasi.Tahap persiapan berupa pembuatan leaflet dan spanduk, pertemuan dengan instansi tempat dilakukannya kegiatan pengabdian masyarakat yaitu pertemuan dengan kepala puskesmas dan penanggung jawab program PTM di Puskesmas Rejosari Pekanbaru, menetapkan tempat dan jadwal kegiatan hingga melakukan persiapan pelaksanaan kegiatan penyuluhan kesehatan. Tahapan pelaksanaan yaitu pelaksanaan kegiatan pengabdian masyarakat yaitu memberikan ceramah dan FGD kepada kader dan masyarakat, sementara tahap monitoring evaluasi dilakukan dalam bentuk Pos test peningkatan pengetahuan setelah diberikan penyuluhan. Untuk Pengukuran tekanan darahnya dibantu oleh seorang perawat dan dilaksanakan setelah di lakukan penyuluhan.

\section{HASIL DAN PEMBAHASAN}

Kegiatan Pengabdian Kepada Masyarakat mengenai peningkatan pengetahuan masyarakat terhadap penyakit hipertensi dan pemeriksaan tekanan darah di RW 03 Kelurahan Limbungan Baru Kec. Rumbai Pesisir Kota Pekanbaru, Riau diikuti oleh masyarakat, kader dan juga tokoh masyarakat. Kegiatan Pengabdian ini dilaksanakan pada tanggal 30 Januari Tahun 2021 yang dimulai pukul 09.00 WIB sampai dengan 12.00 WIB. Pengabdi berkoordinasi dengan Kepala Puskesmas dan Lurah dan Ketua RW 03 untuk perizinan kegiatan pengabdian tersebut. Kegiatan pengabdian masyarakat tentang hipertensi dan pengukuran tekanan darah sangatlah efektif dan tepat dilaksanakan di Kelurahan Limbungan Baru RW 03 karena di tempat tersebut masih banyak Masyarakat yang rendah pengetahuannya tentang pencegahan hipertensi dan masyarakat dalam kondisi pandemik Covid-19 ini tidak pernah lagi memperoleh informasi kesehatan terutama mengenai hipertensi dikarenakan posyandu lansianya selama pandemic tidak aktif dan masyarakat mau pergi kepuskesmas takut tertular covid-19. 


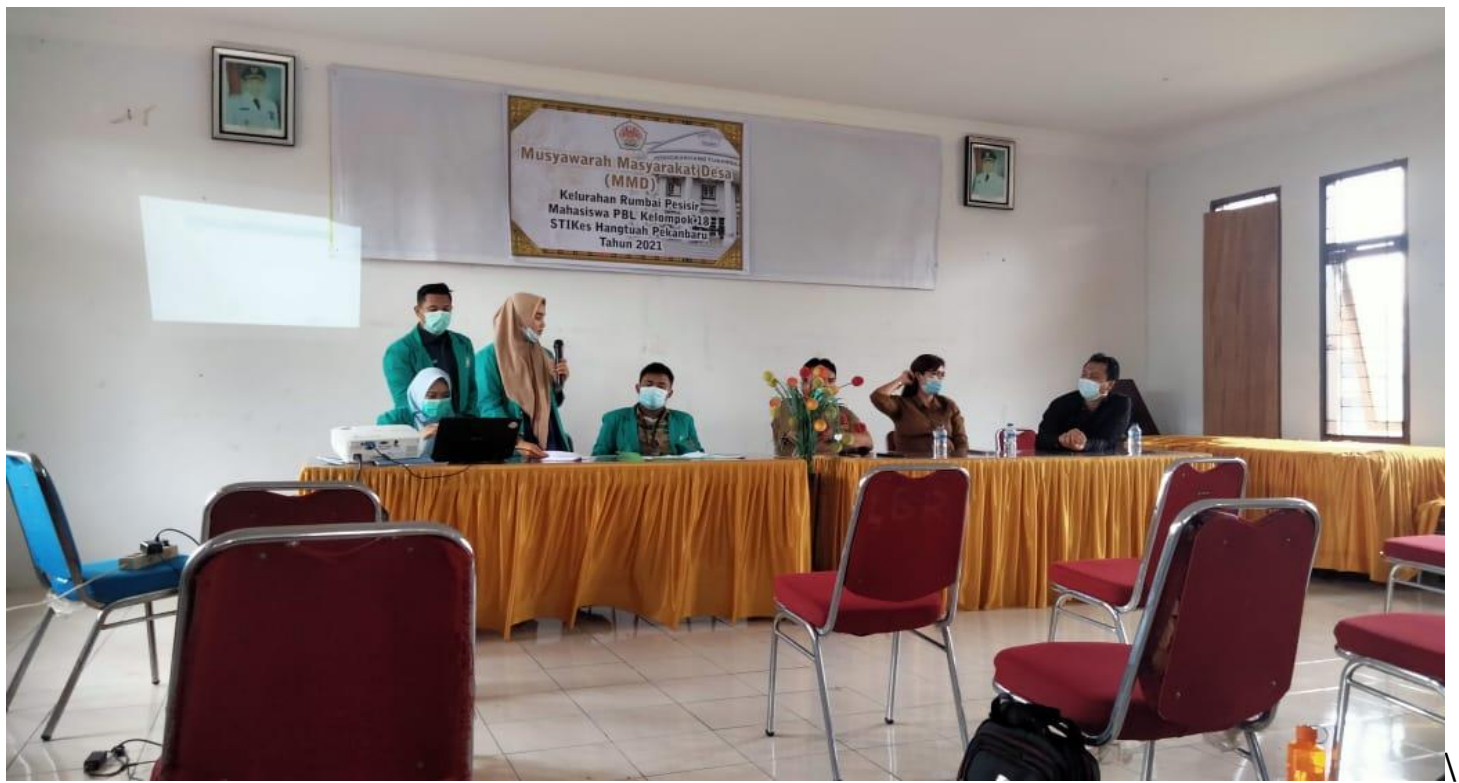

Gambar 1. Pertemuan dengan Kepala Puskesmas dan Pihak kelurahan

Bentuk kegiatan Pengabdian yang dilaksanakan adalah sosialisasi tentang pencegahan penyakit hipertensi, pemberian satu set alat pengukur tekanan darah dan pemeriksaan tekanan darah yang dilakukan secara tatap muka dengan tetap menerapkan protokol kesehatan. Sebelum diberi materi tentang penyakit hipertensi beserta pencegahannya, pengabdi melakukan pemeriksaan tekanan darah terlebih dahulu dan memberikan beberapa pertanyaan terlebih dahulu (Pre Test) untuk mengetahui pengetahuan masyarakat tentang hipertensi. Dari hasil tersebut dapat terlihat bahwa dari 27 orang yang mengikuti kegiatan tersebut, hanya 17 (63\%) peserta yang mengetahui apa itu penyakit hipertensi beserta bagaimana cara pencegahannya (tabel 1). Dari 27 orang yang di ukur tekanan darahnya ada sebanyak 7 orang (26\%) yang tekanan darahnya dikategorikan hipertensi, ada 2 orang (7,5\%) yang tekanan darahnya dikategorikan hipotensi dan 18 orang $(66,5 \%)$ yang tekanan darahnya normal (Tabel 2).

Tabel 1. Distribusi Frekuensi Pengetahuan Responden Tentang Penyakit Hipertensi Dan Pencegahannya Sebelum Diberikan Penyuluhan

\begin{tabular}{cll}
\hline Tingkat & \multicolumn{2}{c}{ Pre test } \\
\cline { 2 - 3 } Pengetahuan & F & $\%$ \\
\hline Baik & 17 & 63 \\
Kurang & 10 & 37 \\
\hline
\end{tabular}


Tabel 2. Distribusi Frekuensi Hasil Pengukuran Tekanan Darah Responden

\begin{tabular}{cll}
\hline \multicolumn{1}{c}{ Tekanan } & F & $\%$ \\
\hline Darah & & \\
\hline Normal & 18 & 66,5 \\
Hipotensi & 2 & 7,5 \\
Hipertensi & 7 & 26 \\
\hline Total & 27 & 100 \\
\hline
\end{tabular}

Setelah kami memberikan materi tentang hipertensi lalu diberikan pertanyaan kembali (Post Test). Hasil yang didapat bahwa dari 27 orang peserta yang mengikuti kegiatan tersebut $21(77,8 \%)$ peserta mengetahui dan dapat menyebutkan satu persatu urutan dari materi ataupun pencegahan hipertensi tersebut dan $6(22,2 \%)$ yang belum paham terhadap materi yang diberikan hal ini mungkin disebabkan karena 6 orang peserta ini sebagian adalah lansia sehingga daya mampu menyerap informasinya tidak secepat yang masih mudah dan ibu-ibu yang membawa bayinya tidak fokus sewaktu mendengarkan materinya karena anak bayi yang dibawa rewel saat materi diberikan, selain itu tingkat pendidikan peserta juga masih banyak yang tamat SD sehingga berpengaruh terhadap daya serap informasi yang diberikan.

Informasi yang diperoleh dari penyuluhan dapat memberikan pengaruh jangka pendek sehingga dapat memberikan perubahan dan peningkatan pengetahuan. Semakin meningkatnya pengetahuan pasien tentang hipertensi akan mendorong seseorang untuk berperilaku yang lebih baik dalam mengontrol hipertensi sehingga tekanan darahnya tetap terkendali, pengetahuan pasien mengenai hipertensi juga berpengaruh pada kepatuhan pasien dalam melakukan pengobatan (Sofiana, 2018). Pengetahuan yang baik tentang hipertensi dapat mempengaruhi perilaku masyarakat dalam mencegah hipertensi (Limbong et al., 2018).

Tabel 3. Distribusi Frekuensi Pengetahuan Responden Tentang Penyakit Hipertensi Dan Pencegahannya Sebelum Diberikan Penyuluhan

\begin{tabular}{cll}
\hline Tingkat & Posttest \\
\cline { 2 - 3 } Pengetahuan & F & $\%$ \\
\hline Baik & 21 & 77,8 \\
Kurang & 6 & 22,2 \\
\hline
\end{tabular}

Berdasarkan penelitian Muthia dkk., didapatkan bahwa terdapat perbedaan yang bermakna antara tingkat pengetahuan akhir dengan tingkat pengetahuan awal pada 
responden yang mendapat penyuluhan kesehatan. Penyuluhan kesehatan merupakan suatu kegiatan yang dapat mempengaruhi perubahan perilaku responden, salah satunya perubahan pengetahuan. Dengan diberikannya penyuluhan maka responden mendapat pembelajaran yang menghasilkan suatu perubahan dari yang semula belum mengetahui menjadi mengetahui dan yang dahulu belum memahami menjadi memahami (Muthia et al., 2015).

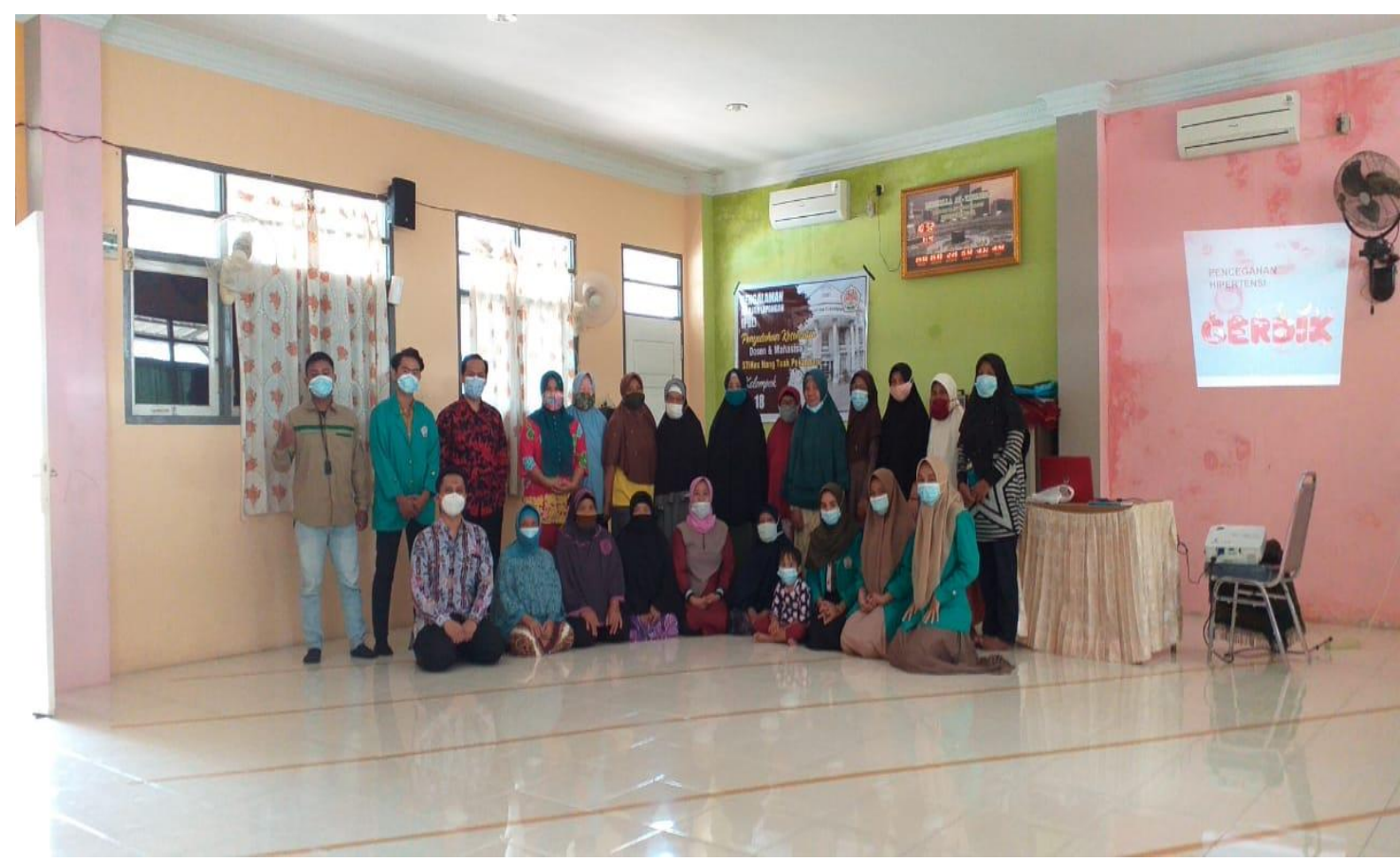

Gambar 2. Foto Bersama peserta penyuluhan

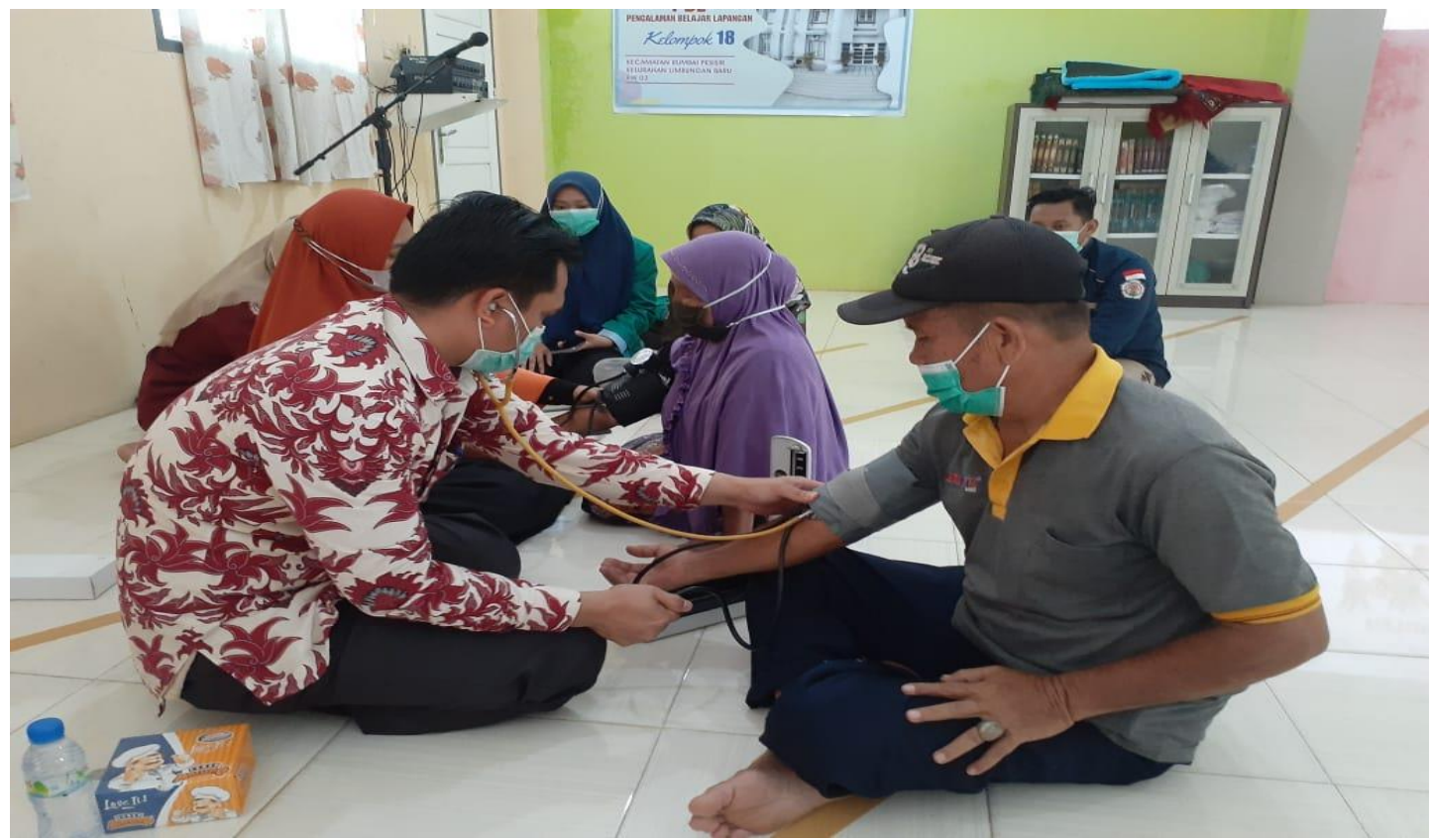




\section{Gambar 3. Pengukuran Tekanan Darah Peserta Penyuluhan}

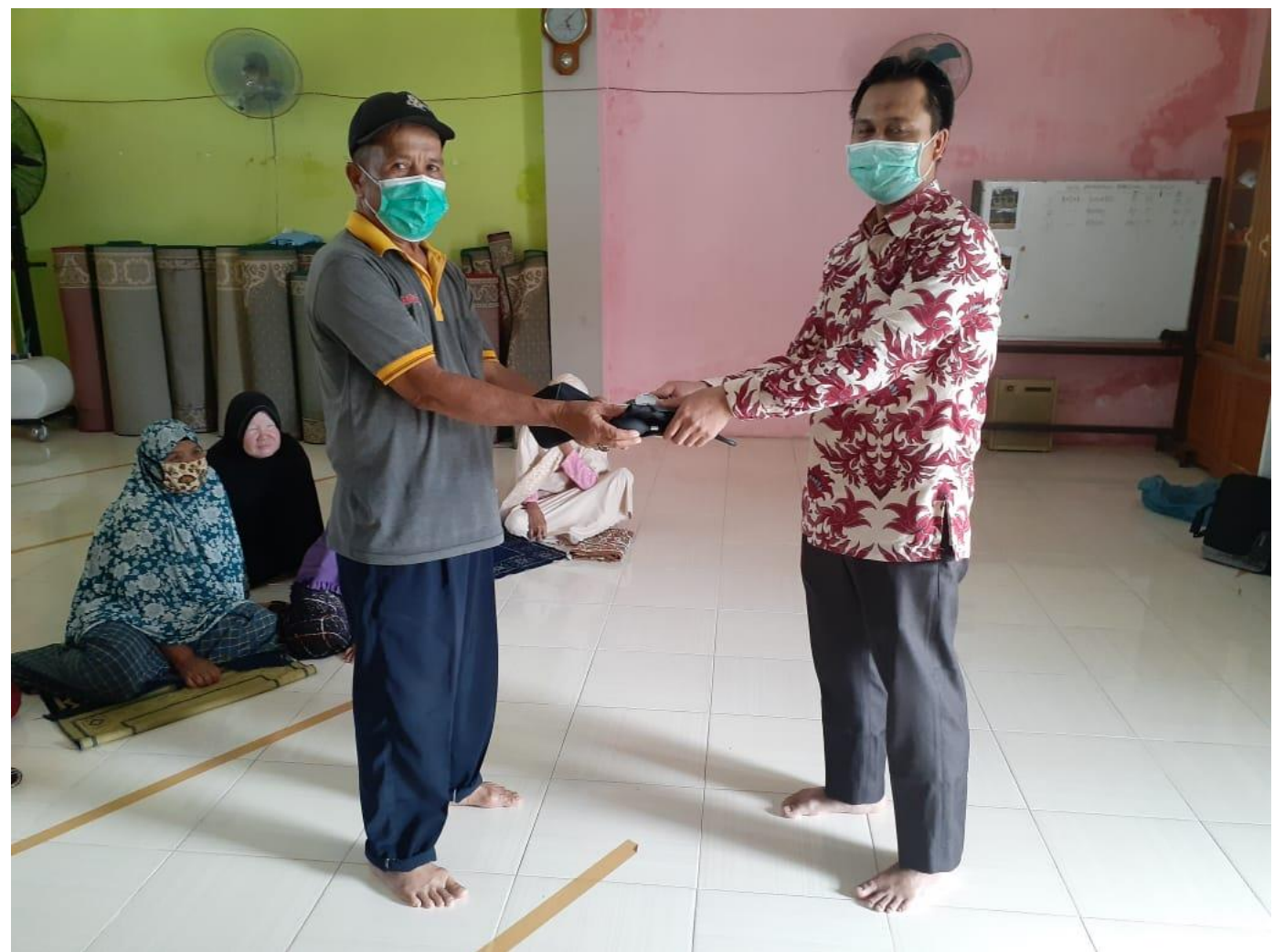

Gambar 4. Penyerahan kepada Ketua RW Satu Set Pengukur Tekanan Darah

Masyarakat RW 03 Kelurahan Limbungan Baru Kecamatan Rumbai Pesisir sangat senang dengan kegiatan pengabdian ini, karena dengan kegaitan ini dapat meningkatkan pengetahuan mereka tentang penyakit hipertensi dan mereka mengetahui kondisi kesehatannya terutama mengetahui tekanan darahnya sehingga bagi yang tekanan darahnya tergolong hipertensi dapat dilakukan tindakan pengobatan segera. Mereka berharap kegiatan ini dapat dilakukan secara berkelanjutan. Tidak hanya masyarakat RW 03 Kelurahan Limbungan Baru Kecamatan Rumbai Pesisir, pihak puskesmas dan kelurahan juga merasa senang dengan kegiatan pengabdian yang kami lakukan karena telah membantu program puskesmas salah satunya adalah program pencegahan penyakit tidak menular.

\section{SIMPULAN}

Terdapat peningkatan pengetahuan masyarakat setelah dilakukan Sosialisasi mengenai hipertensi dan cara pencegahannya di RW 03 Kelurahan Limbungan Baru. Masyarakat mau berkomitmen untuk menerapkan gaya hidup sehat untuk mencegah penyakit hipertensi dan penyakit lainnya. Disarankan kepada Kepada pihak-pihak yang terkait seperti puskesmas 
bekerjasama dengan kepala Desa, untuk dapat memaksimalkan kegaitan penyuluhan tentang hipertensi dan penyakit menualr lainnya serta mengaktifkan kembali kegaitan posyandu lansia dimasa pandemik covid-19 ini secara daring maupun tatap muka dengan tetap menerapkan protokol kesehatan dan kepada masyarakat RW 03 Kelurahan Limbungan Baru Kecamatan Rumbai Pesisir Kota Pekanbaru khususnya yang menderita hipertensi agar dapat rutin mengntrol tekanan darahnya agar tidak terajdi komplikasi dan menerapkan gaya hidup sehat serta aktif mengikuti kegiatan posyandu lansia.

\section{UCAPAN TERIMAKASIH}

Ucapan terimakasih kami sampaikan kepada Pihak Puskesmas Karya Wanita yang telah membantu serta membimbing kami dalam pelaksanaan kegiatan pengabdian masyarakat dan juga kami mengucapkan terimakasih kepada Kelurahan Limbungan Baru yang telah memberikan kesempatan untuk kami melakukan pengabdian masyarakat berupa kegiatan penyuluhan kesehatan dan pendidikan kesehatan kepada masyarakat di Kelurahan Limbungan Baru RW 03.

\section{DAFTAR PUSTAKA}

Adam, L. (2019). Determinan Hipertensi Pada Lanjut Usia. Jambura Health and Sport Journal, 1(2), 82-89. https://doi.org/10.37311/jhsj.v1i2.2558

Depkes RI. (2013). Pokok - Pokok Hasil Riset Kesehatan Dasar tahun 2013. Jakarta.

Faisal, Elvyrah (2011). Faktor Risiko Hipertensi pada Wanita Pekerja dengan Peran Ganda di Kabupaten Bantul (tesis). Prodi Ilmu Kesehatan Masyarakat (Epidemiologi Lapangan) Universitas Gajah Mada, Yoyakarta.

Limbong, V., Rumayar, A., \& Kandou, G. (2018). Hubungan Pengetahuan Dan Sikap Dengan Kejadian Hipertensi Di Wilayah Kerja Puskesmas Tateli Kabupaten Minahasa. Kesmas, $7(4)$.

Muthia, F., Fitriangga, A., \& R.S.A, S. N. Y. (2015). Perbedaan Efektifitas Penyuluhan Kesehatan menggunakan Metode Ceramah dan Media Audiovisual (Film) terhadap Pengetahuan Santri Madrasah Aliyah Pesantren Khulafaur Rasyidin tentang TB Paru T. Jurnal Cerebellum, 2(4), 646-656. http://jurnal.untan.ac.id/index.php/jfk/article/viewFile/23546/18499

Riskesdas, K. (2018). Hasil Utama Riset Kesehata Dasar (RISKESDAS). Journal of Physics A: Mathematical and Theoretical, 44(8), 1-200. https://doi.org/10.1088/1751$8113 / 44 / 8 / 085201$ 
Sofiana, L. Dkk. (2018). Upaya Peningkatan Pengetahuan Tentang Hipertensi Melalui Metode Penyuluhan. Jurnal Pemberdayaan: Publikasi Hasil Pengabdian kepada Masyarakat Volume 2(1), 171-176. 